\title{
The Strategic Impact of Clinical Practice Guidelines in Nursing on the Managerial Function of Supervision
}

\author{
IMPACTO ESTRATÉGICO DAS DIRETRIZES DE PRÁTICA CLÍNICA EM ENFERMAGEM \\ NA FUNÇÃO DE GESTÃO DA SUPERVISÃO
}

\author{
IMPACTO ESTRATÉGICO DE LAS GUÍAS DE PRÁCTICA CLÍNICA EN ENFERMERÍA EN \\ LA FUNCIÓN DE GESTIÓN DE LA SUPERVISIÓN
}

\author{
José Antonio Vinagre Romero', Carmen De Pablos Heredero²
}

\begin{abstract}
Clinical practice guidelines in nursing (CPG-N) are tools that allow the necessary knowledge that frequently remains specialist-internalised to be made explicit. These tools are a complement to risk adjustment systems (RAS), reinforcing their effectiveness and permitting a rationalisation of healthcare costs. This theoretical study defends the importance of building and using CPG-Ns as instruments to support the figure of the nursing supervisor in order to optimise the implementation of $R \& D$ and hospital quality strategies, enabling clinical excellence in nursing processes and cost-efficient reallocation of economic resources through their linear integration with SARs.
\end{abstract}

\section{RESUMO}

As diretrizes de prática clínica em enfermagem (GPC-E) constituem ferramentas que permitem explicitar o conhecimento necessário que com frequência permanece interiorizado nos especialistas. Essas ferramentas são um complemento dos sistemas de ajuste de risco (SAR), que reforçam a eficácia e permitem a racionalização dos custos de cuidados de saúde. Neste estudo teórico, defende-se a importância da elaboração e do uso das GPC-E como instrumentos de apoio para a função da supervisão de enfermagem e o aperfeiçoamento das estratégias de implementação da investigação e desenvolvimento (I+D) e da qualidade hospitalar, tornando possível a excelência clínica em processos de enfermagem e a realocação eficaz em termos de custo-efetividade de recursos econômicos por meio de sua integração alinhada com os SAR.

\section{DESCRITORES}

Supervisão de Enfermagem

Gestão do conhecimento

Análise custo-benefício

Custos e análise de custo

Custos de cuidados de saúde

\section{RESUMEN}

Las guías de práctica clínica en enfermería (GPC-E) constituyen herramientas que permiten la explicitación del conocimiento necesario que con frecuencia permanece interiorizado en los especialistas. Estas herramientas son un complemento de los sistemas de ajuste de riesgo (SAR), los cuales refuerzan su eficacia y permiten una racionalización de los costos de cuidados de salud. En este estudio teórico, se defiende la importancia de la elaboración y de la utilización de las GPC-E como instrumentos de apoyo para la función de la supervisión de enfermería y así, optimizar las estrategias de aplicación de la investigación y desarrollo (I+D) y de calidad hospitalaria, haciendo posible la excelencia clínica en los procesos de enfermería y la reasignación eficaz en términos de costo-efectividad de los recursos económicos mediante su integración alineada con los SAR.

\section{DESCRIPTORES \\ Supervisión de Enfermería \\ Gestión del conocimiento \\ Análisis costo-beneficio \\ Costos y análisis de costo \\ Costos de la atención en salud}

${ }^{1}$ University degree in Nursing. University Master's in Business Administration. PhD student in Business Administration. Nursing Supervisor at the Hospital Universitario La Paz. Madrid, Spain. joseantonio.vinagre@salud.madrid.org ${ }^{2}$ PhD in Economics and Business Sciences. Lecturer at the Faculty of Legal and Social Sciences of the Universidad Rey Juan Carlos, Vicálvaro Campus. Director of the Official Master's degree on the PhD Programme in Business Administration. Madrid, Spain. carmen.depablos@urjc.es 


\section{INTRODUCTION}

The socio-economic and budgetary control scenarios currently found in healthcare systems are increasingly requiring the development of management strategies that are based on principles of effectiveness and efficiency and contribute to the translational application ${ }^{(1)}$ of scientific evidence to nursing, as well as providing a very valuable tool for optimising the costs ${ }^{(2)}$ per care process.

The literature offers many references relating to the creation of clinical practice guidelines in the areas of medicine $^{(3)}$ and nursing ${ }^{(4)}$, but, to our knowledge, there is little on the contribution of clinical practice guidelines in nursing (CPG-N) as a complement to risk adjustment systems ${ }^{(5)}$ (SAR). Since the complexity of the case load is increasing due to advances in knowledge and the availability of scalable healthcare technologies, the use of SARs (Diagnosis Related Groups, Disease Staging Scale, Patient Management Categories, Relative Intensity Score, etc.) is even more critical when estimating the therapeutic intensity and the human resources (HR) and material resources (MR) to be employed, in order to implement management accounting systems with which to define costs that are grouped by diagnostic category and a budgetary planning that matches actual consumption.

The proper management of intellectual capital and its tacit component ${ }^{(6)}$ (characteristic of healthcare organisations) would significantly contribute to the achievement of efficiency. It is here that the function of the supervisor constitutes a link of unquestionable value as the figure who mediates and integrates the different courses of action that make up the process of patient care. Ensuring the wellbeing of the healthcare customer involves grouping together, in a timely manner and due form, multi-layered care-related tasks and criteria for rationalising management in terms of clearly economical consumption linked directly or indirectly to core competencies ${ }^{(7)}$. In this way, costs can be refined through evidence-based practices ${ }^{(8)}$, promoting the development of prospective forecasts that will advance the state of the art.

Using this method, the function of the supervisor, as the visible head of nursing teams, would change from merely distributing resources to assigning them, and therefore playing a critical part in negotiating the institution's budget. This line of thought is considerably strengthened if we consider one of the main problems threatening the sustainability of the healthcare system: the increasing chronification of health problems, a process that mainly involves lengthy, quality nursing care, to the detriment of the invasive and intensive procedures that are more closely related with medical practice, and significantly higher costs.
Therefore, the main aim of this theoretical study is to defend the importance of building and using CPG-Ns as instruments to support the figure of the nursing supervisor in order to optimise the implementation of R\&D and hospital quality strategies, enabling clinical excellence in nursing processes and cost-efficient reallocation of economic resources through their linear integration with SARs.

The document is organised around a main body that constitutes the focus of the discussion on management strategies in multi-referential knowledge environments. After this, it presents a series of conclusions where the main reflections are compiled. Finally, it ends in a bibliography that supports the proposals made.

\section{Management Strategies In Multi-Referential Knowledge Environments}

The development of strategies for supervision-related economies of scale and scope starts with direct intervention by promoting CPG-Ns. Their development brings a series of innovations to the practice of nursing that have little to do with natural competence, if we take into consideration the defeat of the healthcare model that tends toward the generalisation of a public quasi-market with an internally managed power system, typical of liberal and economically-focused models, whose aim is to achieve optimally efficient and effective results. This working approach is supported by process management and the re-engineering of these same processes ${ }^{(9)}$.

Therefore, in order to set appropriate standards of use that will articulate the framework of the CPG-Ns and contribute to containing and lessening variability in nursing practice, it is necessary to follow a methodology of the RAND/UCLA ${ }^{(10)}$ type. This methodology will not only make for a consensual document with international recognition and widespread validation, but will also enable benchmarking and help meet the gold standard of the audience segment addressed. This series of CPG-N-based processes therefore provides the leadership needed to champion pan-institutional standardisation projects. CPG-Ns are, therefore, a synthesis tool that helps to clarify the tacit or implicit knowledge residing in the workforce ${ }^{(11)}$.

Standardisation offers a series of added advantages in economic terms, as each process can be assigned a series of costs that can be defined by means of standard or direct and indirect cost models, depending on their degree of historical development. In this way, the added costs for highly uncertain scenarios are reduced and the preparation of investment studies is facilitated. These studies tend to extend from the process to its sub-processes that occur less frequently but are intimately linked to the main process and have a strong element of tertiary care, which can lead, if not forecast correctly, to a significant diversion of the resources allocated. 
Similarly, the explicit recording of each process helps to simplify management control within the analytical accounting of the institution. The consumption resulting from nursing care can be monitored practically in situ with the help of ad hoc healthcare information systems (HIS).

In regard to SARs, the result of this procedural tool is to gain visibility for the operating costs of specific nursing processes within the main pathology, which tend to be very variable in terms of the knowledge capital held by the nursing professional who is responsible for the patient at a given time. This consideration gains greater weight if we take into account the fact that healthcare institutions have work models that are characterised by combining continuing care and shift work; in other words, there are breaks in the flow of the knowledge applied to each action on each patient.

The above is extremely important for optimum resource administration in the departments under the control of the supervisor. In fact, if the resources to be consumed can be pre-set by considering margins of deviation that can be revised in the light of the series of care processes offered by the department in the past, and if they are correctly implemented based on the evidence from the CPG-Ns ${ }^{(12)}$ in use, negative costs can be obtained that may be reinvested in processes of expansion or in improving the department's available equipment, facilities or staff, which fits perfectly into the philosophy of internally managed competition.

In other words, CPG-Ns stand as instruments that complement the refinement of the SARs most in use, such as Diagnosis Related Groups (DRG), which are based on general diagnostic categories but do not pay attention to the financial repercussions brought on by the variability in the provision of nursing care, which depends on the degree of evidence and/or knowledge operationally expressed in healthcare practices.

This entire task must be carried out while paying careful attention to the possible diseconomies that could appear as a result of the designs, so as to encourage a change from the much feared professional bureaucracies to ad hoc bureaucracies ${ }^{(13)}$, which are more flexible and more in agreement with performance matrix lines.

These interventions, led by department supervisors, have another series of notable influences in monetary terms and on such vital aspects as the economic assessment of healthcare technologies applied to nursing care and even on the creation of joint ventures between departments and institutions to exercise a monopolistic power over directly purchased, storable/non-storable hospital items intimately related to the profession.

In fact, drawing up evidence-based CPG-Ns ${ }^{(12)}$ leads to the rationalisation of spending on healthcare through partial studies $^{(a)}$ or complete studies ${ }^{(b)}$ of ex-ante and ex-post

\footnotetext{
(a) Description of costs and/or consequences, assessment of efficiency, effectiveness and/or usefulness and cost analysis.

(b) Cost-minimisation analysis, cost-efficiency/effectiveness/usefulness/ benefit analysis.
}

economic impact assessment. By applying the methodology of health economics, it is possible to achieve a considerable reduction in the available catalogue by eliminating duplicate references that do not produce savings and do not result in a reliable improvement of the patient's current state and future quality of life. Captive markets are also avoided when one has objective data that guarantee the replacement of technologies and cost-efficient and cost-effective investment.

When joint ventures are created between departments within the same institution but belonging to different services (for temporarily shared process items) or between different institutions belonging to the same or different services (for items shared to a greater or lesser degree), this practice of excellence leads to an additional increase in the monopolistic position of the healthcare sector by imposing competitive rivalry on external suppliers to reach higher standards of quality at affordable prices, thus permitting the transfer of savings to the overall financing of the department(s) and institutions(s).

All of the above is in line with the new research focus, which aims to defend nursing practice in a future that is already part of everyday life, and in which departmental supervision is a critical motivating, promotional and managerial factor.

The implementation of CPG-Ns is therefore the fabric on which translational research projects ${ }^{(1)}$ are based. These projects would have a notable effect on hospital quality and R\&D strategies, contributing to the achievement of clinical excellence in nursing processes.

Research in itself is therefore an excellent stimulus and professional development system (SPDS) in organisations where knowledge is characterised by a high degree of intellectual and relational capital ${ }^{(14)}$, as research permits the simultaneous development of both the institution and the individual and is expressed in the form of visible results in the patient.

Based on this statement, incremental strategies for scientific production are proposed that will result in the creation of new knowledge ${ }^{(15)}$ through cooperation agreements between clinical research centres and care units, based on the continuing improvement of the processes inherent in nursing that have a strong impact on surrogate end points and outcomes, after their feasibility and return on investment have been assessed.

Related to the points in the previous paragraph, clinical effectiveness and outcomes research ${ }^{(16)}$ is a scientific development that is applicable to the practice of nursing using evidence-based CPG-Ns ${ }^{(12)}$. It seeks to determine which nursing care is needed for each patient at any given time and to apply this research to creating new knowledge that will improve decision making and care provision so as to optimise the results in patients.

Based on the above, it is necessary to progress toward the implementation of prospective training plans and the 
use of the portfolio as a method to evaluate teaching and summative assessment. Such plans are designed to generate the skills needed to apply the scientific method to all revision initiatives that are inspired by critical reading.

In line with this proposal and because of the transformation of the educational panorama caused by the Bologna process, which standardises university degrees in Europe without discriminating between diplomas ( 3 years) and undergraduate degrees (5 years), a Bachelor's degree (4 years) was created for all these degrees and diplomas, the Degree in Nursing: 240 ECTS. This degree offers the possibility of entering a doctorate after gaining the necessary ECTS credits through a Master's (entry to the 3rd cycle requires 300 ECTS). It was approved in 2011 in the Science, Technology and Innovation Act ${ }^{(7)}$, which articulated the national research networks to bring them into line with European research models and to make the transfer of research results easier. New, excellent opportunities have therefore opened up for registering doctoral theses in nursing, which are reflected in a radical change in professional and scientific motivation.

In regard to the private financing that allows pre- and post-doctoral courses to be taken and visits to be made or part-time dedication to research, it is essential to set up inter-departmental and inter-institutional joint ventures as these will make it possible to take advantage of the dominant market position of public health institutions. In this way, funds can be obtained from the industry and, in turn, the industry can become a donor to or partner in the project, encouraging the spread of R\&D cooperation strategies. In addition, an active search must be made for resources through private foundations and institutes so as to promote the patronage of this series of activities ${ }^{(17)}$.

As a result of the above proposals, the question arises of how to incorporate efficient nursing department models that will not lead to a breakdown in the institutional management unit, bearing in mind current trends in clinical management, which advocate the above-mentioned introduction of managed competition and the abandoning of management models based on hierarchical authority and control.

Within the managed care approach ${ }^{(18)}$, the idea of clinical management units (medicine/nursing) is taking shape. Their view is organised upon population management criteria, such as disease management ${ }^{(19)}$, for which the organisational component of high-performance te$a m s^{(20)}$ is essential. Disease management builds on the idea of continuity of healthcare in that this continuity can be managed formally by using operational procedures, guidelines and protocols. It is therefore understood that healthcare would be coordinated in a structured manner through primary, secondary and tertiary care ${ }^{(21)}$. The potential of this technique, when understood as an organisational principle, is crucial for patients as it guarantees uninterrupted, inter-level care and decreases the use of unsuitable treatments.
In fact, it is a question of reinforcing the concept of accountability ${ }^{(22)}$ and transferring it to the case load of the department. According to this concept, there is joint responsibility for and research into the results that this accountability brings (in economic and care terms) to the health of the population receiving the services offered in the department's portfolio.

Regardless of dogmatism, this means a transition from the concept of health as a public asset to health as a private asset; in other words, progressing from an obligation to provide means to an obligation to produce results as an outcome of the application of evidence-based nursing management practices that focus on effectiveness and results.

\section{FINAL CONSIDERATIONS}

The management of multi-referential knowledge environments requires tools capable of bringing efficiency to the processes to which they are applied. The literature concerned with the redesigning of business processes can help us to understand real needs from the perspective of the healthcare services and to take advantage of the opportunities stemming from technological and procedural possibilities. This paper brings together a set of reflections on the role that the supervisor must take on when encouraging, creating and promoting clinical practice guidelines in nursing, and their subsequent use.

These practices are mechanisms that complement healthcare risk adjustment systems and therefore help to optimise operating costs. From our analysis, CPG-Ns offer an opportunity to support research projects that can have a positive impact on the pursuit of clinical excellence resulting from nursing processes. When applying this type of tools, we must take into account a set of variables that influence their use. Among these variables, we can highlight the objectives sought by any organisation, the types of relationships and communication between teams, the types of shared tasks and the professional profiles and attributes of the various members of the team. Management by objectives, the management of diversity and a leadership style that fits the profile of the available resources can help to manage the resistance that is logically going to appear when efforts are made to impose change and these tools are applied.

As future lines of research, we should highlight the importance of an analysis of the state of the art, in terms of the development of CPG-Ns and evidence-based nursing practices, at various national and international reference centres. This analysis would lead to the development of studies to determine which organisational excellence routines can be exported and implemented in other healthcare organisations whose organisational models differ (both in the type of legal entity and in the applicable scientific paradigms) but are complementary and could potentially fit. 
The reflection offered here initially emerged from the direct observation of the practice of nursing. In fact, nursing performance is not characterised by the presence of evidence-based clinical practice guidelines. Instead, it is dominated by routine, historically based procedures with slight modifications brought about by the introduction of innovations that disrupt the knowledge or the procedures, which are the only innovations that overcome resistance to change.

With CPG-Ns, knowledge is standardised, the variability of nursing practices is lessened, a solid foundation is built on which to base subsequent research into nursing care, there is progress towards excellence in care, incremental innovation is promoted, relational capital is strengthened, a cost curve is drawn for procedures that allow for budgetary constraints, the construction of economies of scale and scope is facilitated, an economic assessment of the technologies used in nursing is carried out, etc.

In the end, it is a question of nursing supervisors using these tools decisively to exercise their function, which is the management of care quality and the economic and financial management of the resources under their command. Making the operating costs incurred by nursing visible would ease the transition of the role of supervisor from a mere distributor of resources to the assigner of these resources with de facto and de iure power over the department's budget negotiations. This change would feed back as a rise in quality based on the attainment of real, measurable and comparable objectives.

All this means that the role of supervisor becomes a profession, a professional category that requires a com-

\section{REFERENCES}

1. Pronovost PJ, Berenholtz SM, Needham DM. Translating evidence into practice: a model for large-scale knowledge translation. BMJ. 2008;337:a1714.

2. Woolf SH. The meaning of translational research and why it matters. JAMA. 2008; 299(2):211-3.

3. rimshaw JM, Russell IT. Effect of clinical guidelines on medical practice: a systematic review of rigorous evaluations. Lancet. 1993;342(8883):1317-22.

4. Thomas LH, McColl E, Cullum N, Rousseau N, Soutter J. Clinical guidelines in nursing, midwifery and the therapies: a systematic review. J Adv Nurs. 1999; 30(1):40-50.

5. Peiró S. Métodos de medición de casuística y ajuste de severidad y riesgos. En: Gimeno JA, Repullo JR, Rubio S, directores. Manuales de dirección médica y gestión clínica: gestión clínica desarrollo e instrumentos. Madrid: Ed. Díaz de Santos; 2006. p. $145-200$.

6. Grant RM. Toward a knowledge-based theory of the firm. Strat Manag J. 1996; 17(SI):109-22. mand of health economics and other related sciences, such as epidemiology, statistics, clinical management, clinical governance, public health, etc., as well as some minimum requirements of quality scientific production and research into results. All of the above means a cultural revolution that involves the maturity and independence of the profession and of nursing managers as regards the other echelons of the healthcare system.

It therefore means an exceptional qualitative leap in professional level, which would include acknowledging the importance of nursing as a professional force that generates a series of benefits and costs that must be weighed from an economic point of view when it comes to implementing its function as a player in healthcare. In fact, it embraces the entrepreneurial facet of nursing management. All of this is of vital importance if we take into account the already entrenched chronification of diseases, which has led to an increase in the specific weight of the costs arising from nursing care.

However, a series of cultural barriers must be overcome. They are the main limitation to the assumption of this new role that nurses must play as a group and their supervisors as controllers. These barriers arise from the view of the profession as a vocation, which clashes with the efficiency-oriented thinking of nursing as production. The only way to overcome this resistance is through the gradual introduction of management tools into pre-and postgraduate education, as well as continuing education at the professional level. These tools will become commonplace when they are considered to be normal, necessary tools for day-to-day healthcare practices.

7. España. Jefatura del Estado. Ley 14/2011, de 1 de junio, de la Ciencia, la Tecnología y la Innovación. Bol Oficial Estado [Internet]. 2011 jun. [citado 2011 nov. 22];(131). Disponible en: http://www.boe.es/boe/dias/2011/06/02/pdfs/BOEA-2011-9617.pdf

8. Thompson C, Cullum N, McCaughan D, Sheldon T, Raynor P. Nurses, information use, and clinical decision making: the real world potential for evidence-based decisions in nursing. Evid Based Nurs. 2004;7(3):68-72.

9. Hammer M. Reengineering work: don't automate, obliterate. Harvard Bus Rev. 1990; 68(4):104-12.

10. Fitch K, Bernstein SJ, Aguilar MS, Burnand B, LaCalle JR, Lazaro $P$, et al. The RAND/UCLA appropriateness method user's manual [Internet]. Santa Monica (CA): RAND Corporation; 2001 [cited 2011 Nov 25]. Available from: http://www.rand. org/pubs/monograph_reports/MR1269

11. Nonaka I, Takeuchi H. The knowledge-creating company. Oxford (UK): Oxford University Press; 1995. 
12. Lacerda RA, Nunes BK, Batista AO, Egry EY, Graziano KU, Angelo $\mathrm{M}$, et al. Evidence-based practices published in Brazil: identification and analysis of their types and methodological approaches. Rev Esc Enferm USP [Internet]. 2011 [cited 2012 Mar 25];45(3):777-86. Available from: http://www.scielo.br/ pdf/reeusp/v45n3/en_v45n3a33.pdf

13. Mintzberg H. La estructuración de las organizaciones. Barcelona: Ariel; 2002.

14. Bontis N. Intellectual capital: an exploratory study that develops measures and models. Manage Decis. 1998;36(2):63-76.

15. Smith KG, Collins CJ, Clark KD. Existing knowledge, knowledge creation capability, and the rate of new product introduction in the high-technology firms. Acad Manage J. 2005;48(2):346-57.

16. Lauer MS, Collins F. Using science to improve the nation's health system: NIH's commitment to comparative effectiveness research. JAMA. 2010;303(21):2182-3.

17. Nishtar S. Public-private 'partnerships' in health: a global call to action. Health Res Policy Syst. 2004;2(1):5.
18. Porter $\mathrm{ME}$, Olmsted $\mathrm{E}$. Redefining health care: creating valuebased competition on results. Boston (MA): Harvard Business School Press; 2006.

19. McCall N, Cromwell J. Results of the Medicare Health Support disease-management pilot program. N Engl J Med. 2011;365(18):1704-12.

20. Hartog D, Verburg RM. High performance work systems, organisational culture and firm effectiveness. Hum Res Manage J [Internet]. 2004 [cited 2012 Mar 24];14(1):55-78. Available from: ftp://ftp.sapco.ir/eBooks/j.1748-8583.2004. tb00112.x.pdf

21. Bengoa R. Tendencias recientes y reformas de los sistemas de salud. Mercados internos con competencia y sin competencia y los sistemas integrados de salud. An Sist Sanit Navar. 1998;21(2):197-202.

22. O'Hagan J, Persaud D. Creating a culture of accountability in health care. Health Care Manag (Frederick). 2009;28(2):124-33. 